\title{
Beeinflussen Narkotica der Fettreihe die Wassermannsche Reaktion?
}

\author{
Von \\ Siegfried Maass.
}

(Aus der Landes-Heil- und Pflegeanstalt Dösen bei Leipzig

[Direktor : Geh. Medizinalrat Dr. Lehmann].)

(Eingegangen am 18. April 1914.)

F uchs ${ }^{1}$ ) teilte an einer Versuchsreihe von 16 Fällen kürzlich mit, daß Paraldehydgaben die vorher positive Wassermannsche Reaktion im Sinne einer vorübergehenden mehrweniger starken Hämolyse zu beeinflussen vermögen. Veranlaßt wurden seine Versuche durch die Resultate von Craig und $\mathrm{Nichols}{ }^{2}$ ) sowie die von $\mathrm{Hough}^{3}$ ), welche gefunden hatten, daß die Wassermannsche Reaktion nach Alkoholaufnahme (Bier, Whisky, 95\% Alkohol) vorübergehend abgeschwächt resp. negativ werden kann.

Die Resultate dieser Autoren waren jedoch keine einheitlichen. Craig und Nichols beobachteten in allen neun Fällen von Lues ein Negativwerden der Wassermannschen Reaktion auf einige Stunden bis zu 3 Tagen nach der Alkoholaufnahme, während Hough bei einem gleich großen Material nur bei einer noch weniger fortgeschritteneren Paralyse eine stärkere Beeinflussung (fast negativ), in drei weiteren Fällen - terminale Paralyse, Hirnlues, Lues bei Dementia praecox eine solche geringer Art fand. Fünfmal blieb die Wassermannsche Reaktion ganz unbeeinflußt. Hough führt seine von den der beiden vorigen Autoren abweichenden Resultate auf die Technik (aktives Serum) sowie besonders auf die Eigenart seines Materials (Psychosen bei Lues resp. luetischer Ätiologie) zurück, welche Voraussetzung bei Craig und Nichols nicht in Betracht gekommen zu sein scheint.

Die Resultate von Fuchs sind deshalb besonders beachtenswert, weil nach diesen sich erwarten läßt, daß schon einmalige Gaben von 5-6 g Paraldehyd die vorher komplette Hemmung der Wasser mannschen Reaktion in partielle bis totale Hämolyse umwandeln können. Unter seinen 16 Kranken befinden sich 12 Fälle von Paralyse verschiedener Progredienz sowie je 2 Fälle von Lues II und III bei Psychose. Die stets abends gegebene Paraldehyddosis betrug 5-6 g, zweimal $10 \mathrm{~g}$

1) Psychol. Neurol. Wochenschr. 15, 41.

2) Journ. of the Amer. Med. Assoc. 5\%. 1911 (zitiert nach Hough).

3) Zeitschr. f. d. ges. Neur. u. Psych. 10, $281 \mathrm{ff}$. 
innerhalb von 3 Stunden. Das Serum war teils kürzere teils längere Zeit vor, und am Morgen nach der Paraldehydgabe untersucht worden; eine sich anschließende dritte Untersuchung (nach 8 Tagen) findet sich nur zweimal angegeben. Der Grad der Wa ss er m a n n schen Reaktion wurde mittels steigender Mengen des 10proz.Komplementgemisches $(0,25,0,5,1,0)$ bestimmt.

Unbeeinflußt im Ausfall der Reaktion blieben fünf Fälle von Paralyse: vier vorgeschritten, die fünfte ausgesprochen, wenn auch jüngeren Datums; ferner eine Lues III mit Psychose. Von den übrigen Paralytikern zeigten fünf eine mittlere Beeinflussung bei 1,0 und 0,5 Komplement, während bei 0,25 die Wassermannsche Reaktion unverändert war; die zwei anderen boten bei 1,0 mittlere Beeinflussung, waren aber nicht weiter ausgewertet. Totale Hämolyse statt vorheriger kompletter Hemmung fand sich in zwei Fällen von Lues II bei Psychose, während der vierte hierhergehörige Fall mittlere Beeinflussung aufwies.?

Diese Befunde schienen wegen ihrer für die Anstaltspraxis wie theoretische Fragen gleich großen Bedeutung der Nachprüfung wert. Diese wurde an 25 Fällen vorgenommen.

Aus der Gruppe der Hypnotica der Fettreihe wurden außer dem Paraldehyd, welcher als polymerisierter Methylaldehyd den Alkoholen schon ferner steht, das Amylenhydrat, der tertiäre Amylalkohol, angewendet. Beide mit um so größerer Berechtigung, weil sie unter den einfacheren und vorzugsweise verwendeten Hypnoticis der Anstaltspraxis den ersten Platz einnehmen. Auch ist Amylenhydrat in dem ebenfalls gebräuchlichen Dormiol mitenthalten. Paraldehyd kam 17 mal zur Anwendung, Amylenhydrat $8 \mathrm{mal}$. Die Gesamtdosis betrug bei ersterem $16-45 \mathrm{~g}$ (in 16 Stunden bis $33 / 4$ Tagen), bei letzterem $12-16 \mathrm{~g}$ (in $16-38$ Stunden). Näheres ist aus der beigefügten Tabelle zu ersehen.

Die Wa sser ma n n sche Reaktion wurde inkl. der üblichen Kontrollenanordnung nach der Originalmethode, jedoch in halben Mengen $(2,5 \mathrm{ccm}$ gesamt), ausgeführt. Da der Hemmungsgrad der Sera gegen mehrere Antigene durch einen früheren Versuch bereits bestimmt war, wurde für diese Versuche nur ein Extrakt angewendet, und zwar der durch seine Empfindlichkeit wie konstante Wirkung bekannte und vielfach verwendete Herzätherauszug nach Fritz Lesser (aus der Tauenzien-Apotheke Berlin). Zur Feststellung einer ev. hämolytischen Wirkung der gegebenen Hypnotica erschien die von Lesser ${ }^{1}$ ) angegebene Technik der quantitativen Wasser ma n n schen Reaktion durch Serumabstufung am geeignetsten. Nach Lesser stehen Serumtitration bei konstanter Antigen- und Komplementdosis und Komplementtitration bei konstanter Antigen- und Serumdosis in annähernd konstantem Verhältnis, wie aus der von Lesser beigegebenen Aufstellung ${ }^{2}$ ) zu ersehen ist. Es

1) Münch. med. Wochenschr. 1914, 2.

2) l. c. 
bot sich so der Vorteil, den Gehalt des Serums an Reaginen nach der Dosis des ersteren direkt beurteilen und gleichzeitig die Resultate mit denen von Fuchs vergleichen zu können. Jedes Serum wurde in den Dosen 0,1,0,07, 0,04 und 0,01 angesetzt. Außerdem wurden die Sera jedes abgeschlossenen Versuches gleichzeitig geprüft, um für letzteren die gleichen Voraussetzungen für Antigen- und Komplementwirkung zu geben. Bei fast jedem Fall wurde die Wassermannsche Reaktion an 3 Sera angestellt, die kurz vor der ersten und einige Stunden nach der letzten Arzneigabe, sowie einen bis einige Tage später abgenommen waren.

Die auf diese Weise gewonnenen Resultate sowie Menge und Dauer des zugeführten Narkoticums sind unter gleichzeitigen kurzen klinischen Daten aus der folgenden Tabelle zu entnehmen.

Für die 21 Fälle von Paralyse hat sich also ergeben, daß die Wasser mannsche Reaktion in 12 Fällen ganz unbeeinflußt blieb. Eine geringe Abschwächung war in 5 Fällen zu beobachten, davon 3 mal bei 0,04, 2 mal bei 0,01. Eine solche stärkeren Grades fand sich 1 mal ab 0,07 Serum und ebenfalls nur $1 \mathrm{mal}$ in der 0.E. 0,1. In Fall 2 fiel die dritte Untersuchung stärker als die beiden ersten Male aus (Pat. verfiel rasch und starb bald), in Fall 14 war das Paraldehydserum stärker gehemmt als vor- resp. nachher, ohne daß hierfür eine greifbare Erklärung möglich gewesen wäre. Bei einer Wiederholung der Wassermannschen Reaktion mit diesen Sera ergab sich das gleiche Resultat.

Berücksichtigt man, daß für gewöhnlich die Wassermannsche Reaktion nur in der O.E. 0,1 ausgeführt wird, so ist für die untersuchten Fälle von Paralyse festzustellen, daß sich unter 21 Fällen nur einmal eine deutliche Abschwächung zu halber Hämolyse gefunden hat; in Betracht käme weiter nur noch der Fall mit Abschwächung bei 0,07. Die fünf Fälle von hämolytischer Beeinflussung bei 0,04 und 0,01 sind praktisch unwesentlich, da es sich um für diagnostische Zwecke nicht in Betracht kommende Verdünnungsgrade und meist nur geringe Unterschiede handelt.

Klinische Gesichtspunkte für die Entstehung dieses Phänomens haben sich aus obigen Untersuchungen nicht ergeben. Die von Hough ausgesprochene Vermutung, daß die Dauer der Krankheit für die Serumbeeinflussung eine Rolle spiele, findet sich in diesen Resultaten nicht bestätigt. Dauer wie Intensität der Erkrankung übten auf den Reaktionsgrad des Serums keinen erkennbaren Einfluß aus. Auch Fuchs hat keine derartigen Unterschiede erkennen können : eine manifeste Paralyse kürzeren Bestehens zeigte keine Beeinflussung, während diese bei einigen fortgeschritteneren Fällen deutlich war. Ähnliches geht aus dieser Tabelle hervor; bei den Sera mit Abschwächung der Wassermannschen Reaktion handelte es sich teils um frischere, teils um ältere Erkran- 


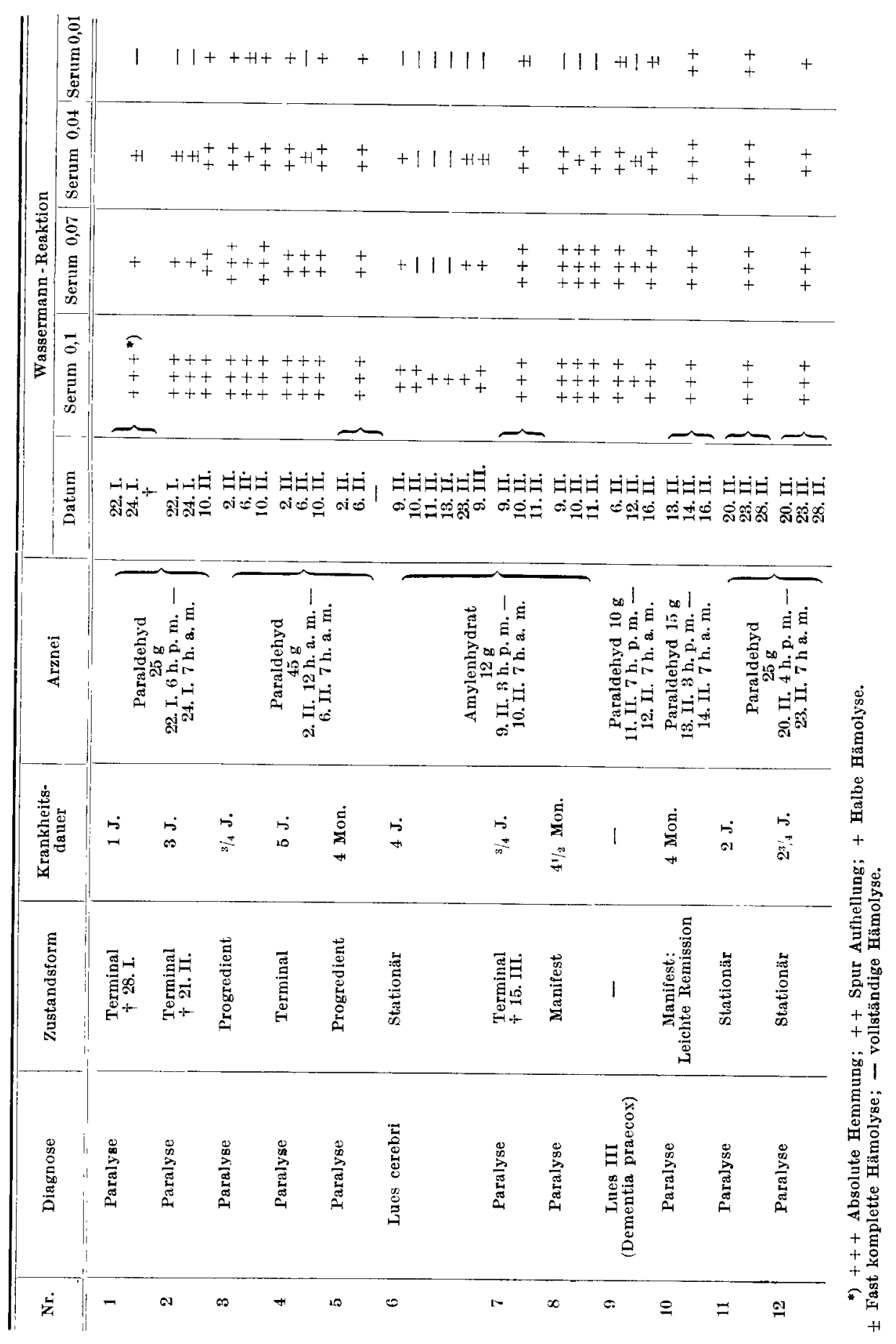


Beeinflussen Narkotica der Fettreihe die Wassermannsche Reaktion?

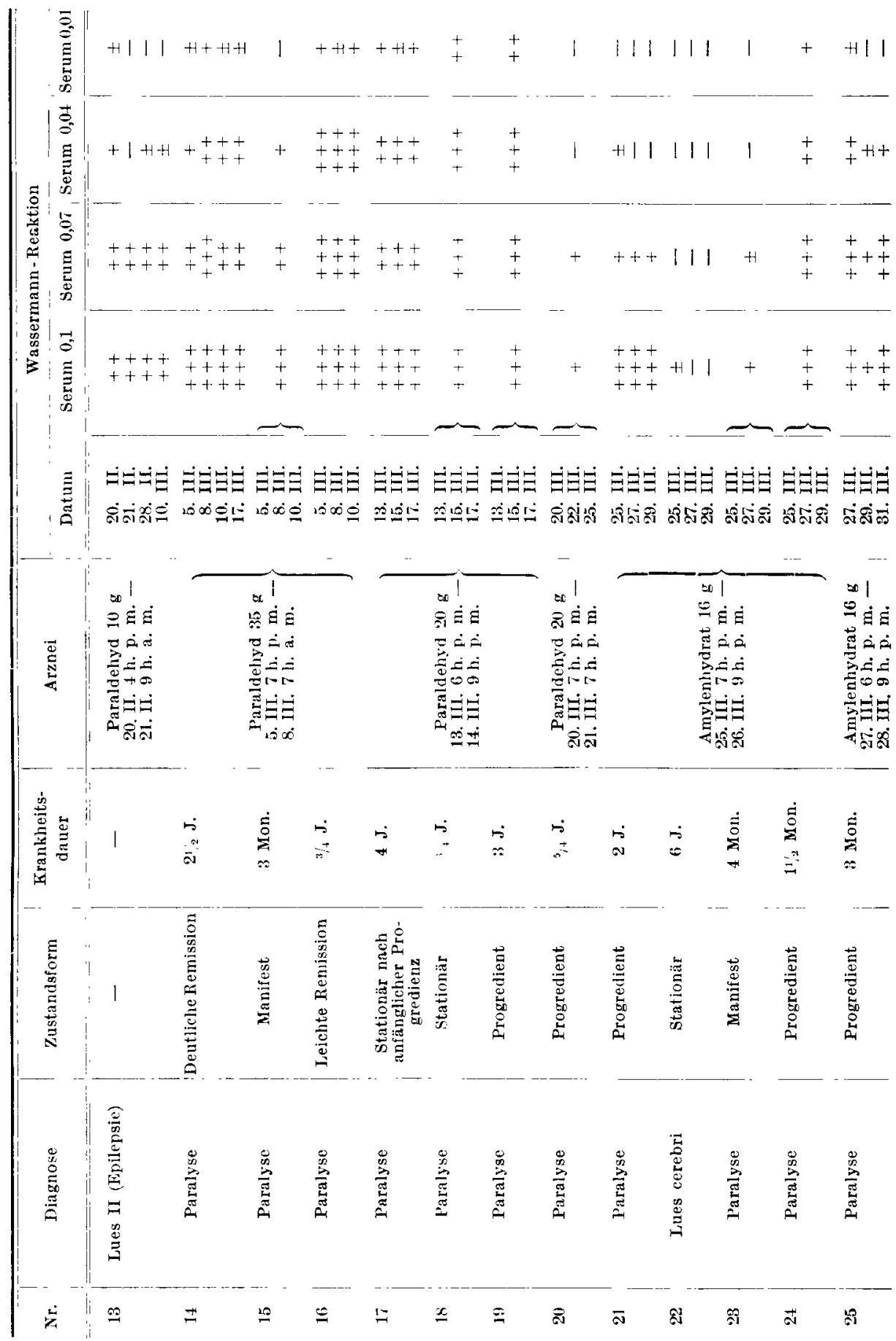


kungen. Auf Berücksichtigung von Alter und Gewicht der Kranken wurde kein Wert gelegt.

Von den beiden Kranken mit Lues cerebri ist der erstere (Fall 6) bemerkenswert, weniger wegen der Intensität als wegen der Dauer der Reaktionsänderung (ca. 14 Tage). Wegen des auffallenden Befundes wurden diese Sera einzeln oder zusammen wiederholt untersucht mit gleichem Resultat. Die Hemmung des zweiten Serums dieser Art war nur sehr gering und wurde komplett nachgelöst. Die beiden Sera von Lues bei Psychose reagierten verschieden: das eine sehr gering, das andere stärker.

Im ganzen betrachtet, ist eine Abschwächung der Wa s ser m a n n schen Reaktion durch Paraldehyd und Amylenhydrat möglich und bei Paralyse, Hirnlues und Lues neben Psychose in einigen Fällen feststellbar gewesen. Am geringsten scheint die praktische Bedeutung dieses Phänomens für die Paralyse zu sein, das Material über die beiden anderen Krankheitsformen gestattet wegen seiner Kleinheit keine persönlichen Schlüsse. In keinem Falle wurde aber eine so weit gehende Beeinflussung gefunden, daß bei der O.E. 0,1 komplette Hemmung in komplette Lösung umgekehrt wurde (Fall 22 kann wegen des geringen Hemmungsgrades nicht berücksichtigt werden). Die praktische Wichtigkeit dieser Erscheinung ist also wahrscheinlich eine geringe resp. fehlende, zumal letztere in gewöhnlich schon kurzer Zeit verschwunden ist. Sie wurde weder so häufig noch so intensiv beobachtet wie von $F u c h s$, führt jedoch zu der gleichen Schlußfolgerung, daß in den der Originalmethode zugrunde liegenden Dosen eine grobe Fehldiagnose unmöglich ist.

Nichtsdestoweniger beansprucht dieses Phänomen größeres theoretisches Interesse. Aus dem vorliegenden Material und auf Grund der quantitativen Serumbestimmung dürfte der Schluß berechtigt sein, da $\beta$ die Abschwächung der Wasser ma n n schen Reaktion vor allem abhängig ist von dem Hemmungsgrad des Serums, von der Menge der in ihm enthaltenen Reagine. Ob daneben die besondere Art der luetischen Erkrankung eine gewisse Rolle spielt — besonders bei Affektion des CNS. — kann nach den bisherigen Erfahrungen noch nicht entschieden werden. Bei einem Vergleich der Resultate von Craigh und Nichols mit denen von Ho ugh und der von Fuchs und von uns beobachteten scheinbar größeren Beeinflußbarkeit der Sera Luetischer gegenüber den von Paralytikern ist die stärkere Reaktionsfähigkeit der Paralytikersera, die allgemein bekannt ist und auch aus dieser Tabelle hervorgeht, zu berücksichtigen.

Während Hough sich auf theoretische Erklärungsversuche nicht näher einläßt, so glaubt $\mathrm{F} \mathrm{u} \mathrm{ch} \mathrm{s} \mathrm{diese} \mathrm{im} \mathrm{Sinne} \mathrm{der} \mathrm{Me} \mathrm{yerschen} \mathrm{Anschau-}$ ungen über die Entstehung der Narkose geben zu können in dem Sinne, daß ,wenn nun Narkotica der Fettsäurereihe, wie z. B. der Alkohol und das Paraldehyd, die Lipoide id est die Antigene zu verändern ver- 
mögen, so kann auch der auf diese umgeänderten Antigene nicht eingestellte Antikörper sich nicht mit ihnen verbinden : es kommt zur Hämolyse." Nach unseren Erfahrungen muß es dahingestellt bleiben, ob die Meyer-Overtonsche Narkosetheorie die allein mögliche und vor allem genügende Erklärung gibt. Damit steht doch nicht im Einklang die von Wolfsoh $n^{1}$ ) und Reicher ${ }^{2}$ ) gefundene Tatsache, daß Narkosesera häufig unspezifische positive Wassermannsche Reaktion geben, was von ersterem ebenfalls auf die Meyer-Orertonsche Narkosetheorie zurückgeführt wird. Da an dieser 'l'atsache, die vielfach, z. B3. von Bruck und Stern ${ }^{3}$ ), Boas und Petersen ${ }^{4}$ ) u. a. bestätigt wurde, nicht zu zweifeln ist. geht hervor, daß die hier in Betracht kommenden Verhältnisse wesentlich komplizierter sein müssen, jedenfalls ist es nicht angängig die gleiche Theorie zur Erklärung zweier entgegengesetzter Phänomene - des Positivwerdens der Narkosesera und des Negativwerdens von Sera nach Paraldehyd - heranzuziehen.

\section{Zusammenfassung.}

Unter 24 Sera mit positiver Wassermannscher Reaktion ließ sich bei quantitativer Serumabstufung 10 mal eine Abschwächung der Reaktion durch Paraldehyd und Amylenhydrat beobachten.

Diese war jedoch in sechs Fällen praktisch ganz unwesentlich, weil sie nur in den stärksten Verdünnungen $(0,04$ und 0,01$)$ oder in geringen Grenzen auftrat. Nur zwei Sera waren in der O.E. 0,1 zu halber Hämolyse abgesehwächt, zwei andere bei 0,07 . In einem Fall blieb das Serum 14 Tage abgeschwächt, sonst $1-3$ Tage.

Die Wirkung des Amylenhydrats schien etwas stärker zu sein als die des Paraldehyds. Dagegen übte die Gesamtdosis des Medikaments keinen erkemnbaren Einfluß aus.

Die scheinbar auch von uns gefundene Tatsache, daß die Sera von gewöhnlichen Luetikern leichter beeinflußbar sind als die von Paralytikern, ist zunächst nur auf die stärkere Reaktionsfähigkeit letzterer Sera zurückzuführen.

Größere praktische Bedeutung dürfte dem Phänomen nicht zukommen, da speziell für die luetischen Erkrankungen des CNS. eine stärkere Beeinflußung der Wasser ma n n schen Reaktion in der Originaldosierung zu den größten Seltenheiten gehören dürfte. Fin Fehlresultat aus diesem Grunde ist also kaum zu befürchten.

1) Deutsche med. Wochenschr. 1910, 505.

$\left.{ }^{2}\right)$ Deutsche med. Wochenschr. 1910, 617.

3) Zeitschr. f. Immunitätsforsch. Orig, 6, 602. S. 514 .

4) Hospitals titenda 1911, Nr. 16. --. Zeitschr. f. Immunitätsforsch. Ref. 1911, 